\title{
Origin of Three Red-Crowned Cranes Grus japonensis Found in Northeast Honshu and West Hokkaido, Japan, from 2008 to 2012
}

\author{
Yoshiaki MIURA $^{1)}$, Junya SHIRAISHI ${ }^{1}$, Akira SHIOMI ${ }^{1)}$, Takio KITAZAWA ${ }^{1)}$, Takeo HIRAGA ${ }^{1)}$, \\ Fumio MATSUMOTO ${ }^{2)}$, Hiroki TERAOKA ${ }^{1,2) *}$ and Hiroyuki MASATOMI ${ }^{2)}$ \\ 1) School of Veterinary Medicine, Rakuno Gakuen University, Ebetsu 069-8501, Japan \\ 2) Tancho Protection Group, Kushiro 085-0036, Japan
}

(Received 19 February 2013/Accepted 12 April 2013/Published online in J-STAGE 26 April 2013)

ABSTRACT. The Red-crowned Crane Grus japonensis is an endangered species that has two separate breeding populations, one in the Amur River basin and the other in north and east Hokkaido, Japan. So far, only two (Gj1 and Gj2) and seven (Gj3-Gj9) haplotypes in D-loop of mtDNA were identified in Japan and in the continent, respectively. We obtained feathers from three cranes found in northeast Honshu. The crane in Akita in 2008, which also arrived at west Hokkaido, had a novel haplotype (Gj10). Another crane in Akita in 2009 showed a heteroplasmy ( $\mathrm{Gj} 7$ and a novel type, Gj12). The third crane in Miyagi in 2010 also showed another type, Gj11. These results suggest that three Red-crowned Cranes appeared in Honshu and west Hokkaido were from the continent.

KEY WORDS: continental population, genetic diversity, Hokkaido, island population, Red-crowned (Japanese) Crane.

doi: 10.1292/jvms.13-0090; J. Vet. Med. Sci. 75(9): 1241-1244, 2013

The Red-crowned (or Japanese) Crane Grus japonensis is one of the most endangered species in the world, with an estimated total population of 2,800 [5]. There are two widelyseparated populations of this species: a migratory population on the east Eurasian continent (the continental population) and a non-migratory population in east (Fig. 1a-d) and north (Fig. 1e, f) Hokkaido, Japan (the island population) [4, 8]. The continental population is primarily distributed along the Amur River basin in Russia and China in summer and migrates to the east coast of middle China and on the Korean Peninsula for wintering [6, 7]. Recently, Red-crowned Cranes were found much more frequently in southwest and central Hokkaido Island. More than 50 cranes, whose origins were unclear, have been recorded between 2001 and 2010 [13].

Mitochondrial DNA (mtDNA) is inherited exclusively from mother to offspring without recombination in birds as well as other vertebrates [1]. Among mtDNA, the D-loop (control region) is a noncoding DNA with a high mutation frequency and best characterized for genetic diversity within a species or subspecies, including Gruinae [11, 12]. Nine haplotypes for the D-loop in Red-crowned Cranes have been reported so far [3]. Only two haplotypes $(\mathrm{Gj} 1$ and $\mathrm{Gj} 2)$ were identified in 15 wild cranes from the island population, while the other seven haplotypes $(\mathrm{Gj} 3-\mathrm{Gj} 9)$ were detected in only 14 captive cranes in some zoos and aquariums in Japan, birds that originated from the continental population [3]. The finding of extremely low genetic diversity in the island population was confirmed by large-scale study with 203 wild

*Correspondence to: Teraoka, H., School of Veterinary Medicine, Rakuno Gakuen University, Ebetsu 069-8501, Japan.

e-mail: hteraoka@rakuno.ac.jp

(C)2013 The Japanese Society of Veterinary Science cranes in our previous study [9] as well as a pilot study with microsatellites [2].

Many Red-crowned Cranes, which origins were unclear, were also observed in Honshu and Shikoku, especially in northeast Honshu in this century. In this study, we had a chance to obtain feathers collected from three Red-crowned Cranes found in Honshu mentioned above to determine their haplotypes. We will show that they were all novel and very different from those of island population, suggesting that these cranes were from the continental population, but not from the island population.

With permission from the Japanese Ministry of the Environment (Tokyo, Japan), two body feathers naturally molted from a subadult Red-crowned Crane (Akita No. 1) were collected in Ogata grassland in Ogata, Akita Prefecture, in 2008 (Fig. 1k). Two primary coverts were also collected from a set of naturally molted feathers of another subadult Redcrowned Crane (Akita No. 2) in Ogata grassland in 2010 (the first molt) and 2012 (the second molt). Two body feathers were obtained from a subadult crane at Kabukuri wetland in Osaki, Miyagi Prefecture in 2010 (Fig. 11) (Miyagi No. 1). For comparison, body feathers were also obtained from 52 adult Red-crowned Cranes kept in Okayama Prefectural Nature Conservation Center in Wake, Okayama Prefecture in 2009. We used the same samples as those in our previous study [9]. Forty five of these captive cranes originated from birds imported from Eurasian Continent (Gj3, 35: Gj4, 1: $\mathrm{Gj} 5,1)$, and 8 cranes were from Hokkaido $(\mathrm{Gj} 2)$ [9].

Mitochondrial DNA was extracted from several pieces of feather follicles as previously described [9]. Extracted DNA was used as a template for polymerase chain reaction (PCR) to produce the whole length of the D-loop with the forward primer $5^{\prime}$-ACCCCATAATACGGTGAAGG-3' and the reverse primer 5'-ACGGTAAGGTTAGGACTAAG-3'. Complete D-loop was sequenced with the dideoxy method 


\section{Hokkaido Island}

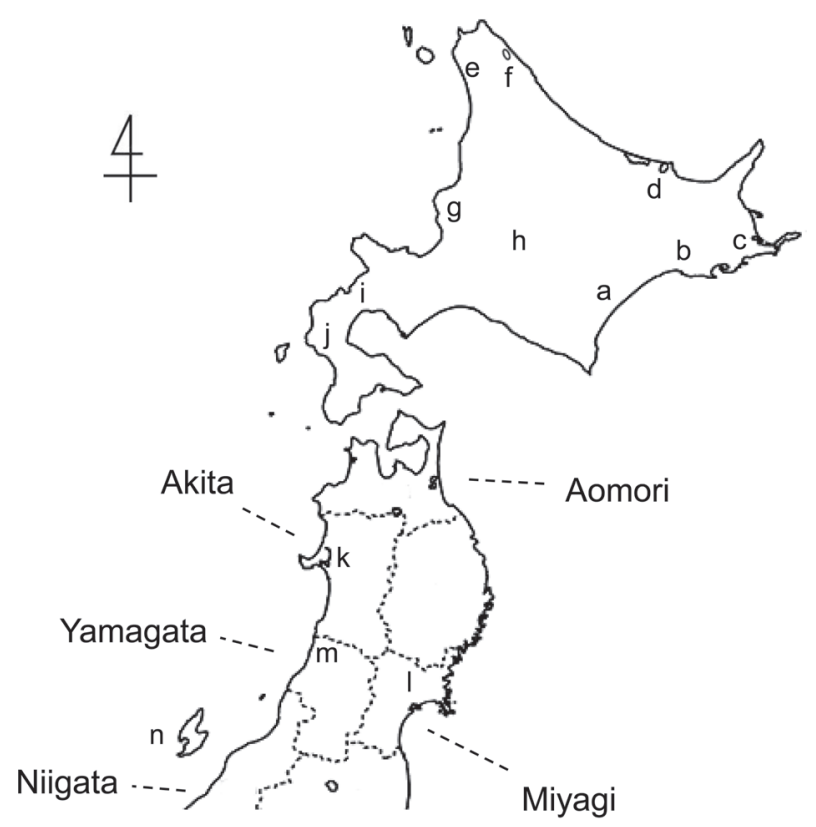

\section{Honshu Island}

Fig. 1. Places cited in Hokkaido Island (Hokkaido Prefecture) and in northeast Honshu Island. a: Tokachi, b: Kushiro: c: Nemuro, d: Abashiri, e: Sarobetsu wetland, f: Kuccharo lake, g: Ishikari, h: Furano, i: Rankoshi, j: Setana, k: Ogata grassland in Ogata, Akita Prefecture, 1: Kabukuri wetland in Osaki, Miyagi Prefecture, m: Tsuruoka, Yamagata Prefecture, n: Sado island in Niigata Prefecture.

as described [9]. The primers used for sequencing were SEQDLF1 (5'-GGCTTTTCTCCAAAACTCGC-3': forward), SEQDLF2 (5'-TCACGTGAAATCAGCAACCG-3': forward) and SEQDLR (5'-ATCTTCAGTGCCATGCTTTG-3': reverse). We repeated these procedures from DNA extraction at least twice for each sample. As the results of crane sexing according to the previous method [9], three cranes were all male.

One subadult crane, which had a characteristic feather pattern on its shoulder and tail region (Fig. 2A), firstly appeared in Ishikari, Hokkaido Prefecture (Fig. 1g) in March 2008. He moved to Ogata grassland in Akita Prefecture (Fig. 1k) through Rankoshi (i) and Setana (j) by May 2008. As he wintered in Ogata grassland in Akita twice by 2010, he was named Akita No. 1. As listed in Table 1, Akita No. 1 showed a haplotype, which was very similar to $\mathrm{Gj} 5$ but novel. It was designated Gj10 (DDBJ Accession No. AB669093). There were only three different nucleotides in Gj10, 23rd to 25th, compared with Gj5, but Gj10 was very different from the two haplotypes in Hokkaido, Gj1 and Gj2. During his stay in Akita, Akita No. 1 wandered about some places in Hokkaido, such as Ishikari (Fig. 1g), Furano (h), Rankoshi (i) and Setana (j) and in northeast Honshu, such as Sado Island,
Niigata prefecture (n) and Tsuruoka, Yamagata prefecture (m). We were able to collect also his small body feathers in Rankoshi in summer of 2010 and confirmed Gj10 haplotype again. Thus, it is suggested that Akita No. 1 came from the continent, and he also arrived at central and southwest Hokkaido. As a particular character, Akita No. 1 was unafraid of humans, and humans could approach to him within a few $\mathrm{m}$. This is inconceivable for other wild cranes, suggesting that Akita No. 1 might have been kept in a facility in the continent before he came to Japan. He was lastly found in Setana in June 2011 and disappeared thereafter. Thus, he stayed in Japan for three years and a month, including a missing period.

Miyagi No. 1 was initially found in a water-filled paddy field near Kabukuri wetland in Osaki, Miyagi Prefecture (Fig. 11) in January 2010, when he was subadult. As he left there in April 2010, he stayed there for about three months. We studied his two flight feathers and confirmed another novel haplotype, Gj11 (AB669094) (Table 1). We were able to find the same haplotype in a Red-crowned Crane kept in Okayama Prefecture. The mother of this captive crane was imported from China to another zoo in Japan and then finally was kept in Okayama Prefecture. Thus, it was thought that Miyagi No. 1 came from the continent.

The other subadult crane (Akita No. 2), which showed short 7 th primary feather (the fourth feather from the outside, Fig. 2B) as a characteristic marker, appeared in Ogata grassland, Akita (Fig. 1k) in March 2009 and moved to Setana (Fig. 1j) in the next month. Although he appeared again in Ogata in June 2010 and stayed there by the end of the year, he wintered twice in Kabukuri wetland, Miyagi (Fig. 11) in early winter of 2011 and 2012. He wandered about the other place in Akita, Aomori Prefecture and west Hokkaido, while he stayed in Akita by December of 2012, resulting in about a year and eleven months in total. Akita No. 2 molted a set of flight feathers and coverts in Ogata grassland twice during this period. After examining his feathers of both the first and the second molt, we found two haplotypes, Gj7 and the other novel type, Gj12 (AB669095) (Table 1), as heteroplasmy of mitochondrial DNA.

The present results suggest that origins of three Redcrowned Cranes appeared in Honshu and west Hokkaido were the continental population. This is the first case, suggesting their continental origins based on the genetic evidence. Stray Red-crowned Cranes had been found occasionally after the late 19th century in Honshu; most of them stayed only for a short period [4]. However, Akita No. 1 and Akita No. 2 stayed relatively long time and visited elsewhere in northeast Honshu and west Hokkaido. This raises possible accidental encounters of cranes from the island and the continental populations. Their crossing could improve scarce genetic diversity in the island population. It is well known that scarce genetic diversity could reduce resistance to environmental changes and various infectious diseases [10]. Conversely, encounters of cranes from both populations could increase the danger of transmission of infectious diseases. This is the serious threat for the island population, which gathers in several places for artificial feeding in winter. Another concern 

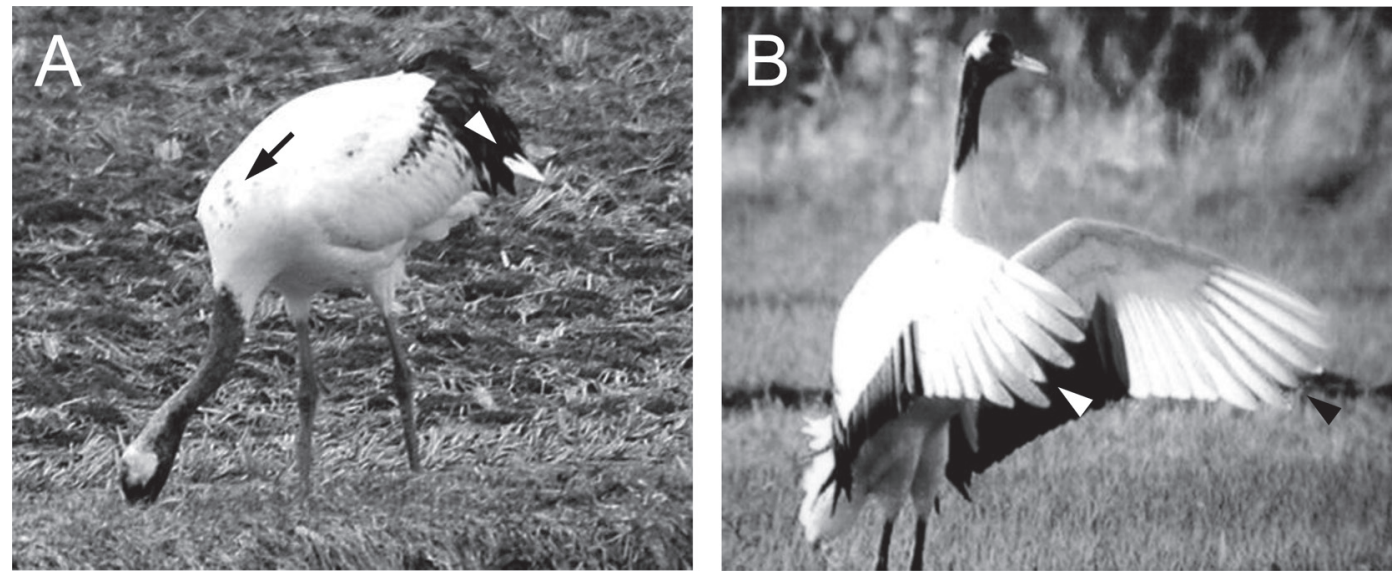

Fig. 2. Photographic images of Akita No. 1 and Akita No. 2. A: Akita No. 1 had black spots on his left shoulder (arrow) and a few white tail feathers sticking out from among the black feathers (arrowhead). B: Akita No. 2 had short 7th primary feathers compared to feathers on both sides (white and black arrowheads).

Table 1. Haplotypes of the mitochondrial D-loop in Red-crowned Crane

\begin{tabular}{|c|c|c|c|c|c|c|c|c|c|c|c|c|c|c|c|c|c|c|c|c|c|c|c|c|}
\hline Haplotype & 23 & 24 & 25 & 49 & 74 & 130 & 166 & 190 & 237 & 239 & 247 & 257 & 274 & 318 & 323 & 402 & 407 & 440 & 550 & 562 & 622 & 808 & 836 & 1000 \\
\hline Gj1 & $\mathrm{T}$ & A & C & A & A & $\mathrm{T}$ & C & C & C & G & G & A & C & $\mathrm{T}$ & G & A & C & C & $\mathrm{T}$ & C & C & C & G & A \\
\hline $\mathrm{Gj} 2$ & - & - & - & - & - & - & $\mathrm{T}$ & - & $\mathrm{T}$ & A & A & - & - & - & A & G & $\mathrm{T}$ & $\mathrm{T}$ & $\mathrm{C}$ & $\mathrm{T}$ & - & $\mathrm{T}$ & A & G \\
\hline $\mathrm{Gj} 3$ & - & - & - & - & - & $\mathrm{C}$ & $\mathrm{T}$ & - & - & - & A & G & - & $\mathrm{C}$ & - & - & - & $\mathrm{T}$ & $\mathrm{C}$ & - & $\mathrm{T}$ & $\mathrm{T}$ & - & G \\
\hline $\mathrm{Gj} 4$ & - & - & - & G & - & - & $\mathrm{T}$ & - & - & - & A & - & - & - & - & - & - & $\mathrm{T}$ & $\mathrm{C}$ & - & - & - & - & G \\
\hline Gj5 & - & - & - & - & - & - & $\mathrm{T}$ & - & - & - & A & - & - & - & - & G & - & $\mathrm{T}$ & $\mathrm{C}$ & - & - & $\mathrm{T}$ & - & G \\
\hline Gj6 & - & - & - & - & - & - & $\mathrm{T}$ & - & - & - & A & - & - & - & - & - & - & $\mathrm{T}$ & & & & & & \\
\hline $\mathrm{Gj} 7$ & - & - & - & - & - & - & $\mathrm{T}$ & - & - & A & A & - & - & - & A & $\mathrm{G}$ & - & $\mathrm{T}$ & & & & & & \\
\hline Gj8 & - & - & - & - & - & - & $\mathrm{T}$ & - & - & - & A & - & $\mathrm{T}$ & - & - & G & - & $\mathrm{T}$ & & & & & & \\
\hline Gj9 & - & - & - & - & - & - & $\mathrm{T}$ & - & - & - & A & G & - & $\mathrm{C}$ & - & - & - & $\mathrm{T}$ & & & & & & \\
\hline Gj10 & C & $\mathbf{T}$ & A & - & - & - & $\mathbf{T}$ & - & - & - & A & - & - & - & - & G & - & $\mathbf{T}$ & C & - & - & $\mathbf{T}$ & - & G \\
\hline Gj11 & - & - & - & - & - & - & - & $\mathbf{T}$ & - & - & $\mathbf{A}$ & - & - & - & - & G & - & $\mathbf{T}$ & C & $\mathbf{T}$ & - & $\mathbf{T}$ & - & $\mathbf{G}$ \\
\hline Gj12 & - & - & - & - & G & - & $\mathbf{T}$ & - & - & $\mathbf{A}$ & $\mathbf{A}$ & - & - & - & $\mathbf{A}$ & G & - & $\mathbf{T}$ & C & $\mathbf{T}$ & - & $\mathbf{T}$ & - & G \\
\hline
\end{tabular}

Whole nucleotide sequences (1-1,165 bp) of mitochondrial D-loop for nine haplotypes reported by Hasegawa et al. (1999), plus three haplotypes identified in this study are shown in bold. The same nucleotides as Gj1 are indicated by [-], while nucleotides different from Gj1 are shown by the corresponding letters. Blanks appearing in Gj5-Gj9 (550-1,000 bp) were not determined. Gj10, Gj11 and Gj12 indicate haplotypes for Akita No. 1, Miyagi No. 1 and Akita No. 2, respectively. Gj12 was identified as a heteroplasmy with Gj7, with a difference in only the 74th nucleotide, in Akita No. 2.

is a loss of genetic independence of the island population, if genetic background between two populations is very different [9]. A large-scale study on the D-loop haplotype with wild Red-crowned Cranes in the continental population is required to clarify genetic diversity in the continent population and their relationship to the island population. Three Redcrowned Cranes found in Honshu Island in this study were all male. As only information of maternal genetics could be obtained with the study of mitochondrial markers like the Dloop [1], other genetic markers, such as microsatellites [2], should also be extensively studied to characterize the genetic background of both populations before and after their crossing. In addition, the other studies also are urgently required, including of anatomical, physiological and immunological aspects in order to clarify the difference between these two populations.
ACKNOWLEDGMENTS. Authors are grateful for Dr. George Archibald for critical reading of this manuscript and valuable comments. We thank Mr. Y. Kagaya and H. Saito who supported us to obtain samples. We also thank Okayama prefecture for many feathers from cranes kept in their facilities. This study was supported by Grants-in-Aid for Scientific Research (B) (21310044) to H. T. from the Japan Society for the Promotion of Science (JSPS), Grant-in-Aid for the High Technological Research Center (Rakuno Gakuen University) from the Ministry of Education to H.T.

\section{REFERENCES}

1. Avise, J. C., Neigel, J. E. and Arnold, J. 1984. Demographic influences on mitochondrial DNA lineage survivorship in animal populations. J. Mol. Evol. 20: 99-105. [Medline] [CrossRef] 
2. Hasegawa, O., Ishibashi, Y. and Abe, M. 2000. Isolation and characterization of microsatellite loci in the Red-crowned Crane Grus japonensis. Mol. Ecol. 9: 1677-1678. [CrossRef]

3. Hasegawa, O., Takada, S., Yoshida, M. C. and Abe, S. 1999. Variation of mitochondrial control region sequences in three crane species, the Red-crowned Crane Grus japonensis, the Common Crane G. grus and the Hooded Crane G. monacha. Zool. Sci. 16: 685-692. [CrossRef]

4. Masatomi, H. 2000. The all of Tancho. Hokkaido Shimbun Press, Sapporo (in Japanese with English legends for figures and tables).

5. Masatomi, H. 2009. Number of Grus japonensis of the world in 2008-09 winter. Tazu 4: 1-6.

6. Masatomi, Y., Higashi, S. and Masatomi, H. 2007. A simple population viability analysis of Tancho (Grus japonensis) in southeastern Hokkaido, Japan. Popul. Ecol. 49: 297-304. [CrossRef]

7. Masatomi, H., Momose, K., Koga, K., Masatomi, Y. and Matsumoto, F. 2008. Breeding status of Tancho Grus japonensis in Hokkaido, 2008. J. Com. Cooperative Res. Center 3: 33-58 (in Japanese with an English abstract, figures and tables).

8. Meine, C. D. and Archibald, G. W. 1996. The Cranes: Status Survey and Conservation Action Plan, International Union for
Conservation of Nature, Gland.

9. Miura, Y., Shiomi, A., Shiraishi, J., Makita, K., Asakawa, M., Kitazawa, T., Hiraga, T., Momose, Y., Momose, K., Masatomi, H. and Teraoka, H. 2013. Large-scale survey of mitochondrial D-loop of the Red-crowned Crane Grus japonensis in Hokkaido, Japan by convenient genotyping method. J. Vet. Med. Sci. 75: 43-47. [Medline]

10. O'Brien, S. J. and Evermann, J. F. 1988. Interactive influence of infectious disease and genetic diversity in natural populations. Trends Ecol. Evol. 3: 254-259. [Medline] [CrossRef]

11. Petersen, J. L., Bischof, R., Krapu, G. L. and Szalanski, A. L. 2003. Genetic variation in the midcontinental population of Sandhill Cranes, Grus canadensis. Biochem. Genet. 41: 1-12. [Medline] [CrossRef]

12. Ponomarev, A. G., Tatarinova, T. D., Bubyakina, V. V., Smagulova, F. O., Morozov, I. V., Kashentseva, T. A. and Solomonov, N. G. 2004. Genetic diversity in Siberian Crane (Grus leucogeranus) based on mitochondrial DNA D-Loop polymorphism. Dokl. Biol. Sci. 397: 321-323. [Medline] [CrossRef]

13. Takeuchi, A., Masatomi, Y. and Matsumoto, F. 2009. Where is Tancho going? - beyond the expansion of their territories. Faura 26: 24-27 (in Japanese). 